Editor's Note: These short reviews of recent JNeurosci articles, written exclusively by students or postdoctoral fellows, summarize the important findings of the paper and provide additional insight and commentary. If the authors of the highlighted article have written a response to the Journal Club, the response can be found by viewing the Journal Club at www.jneurosci.org. For more information on the format, review process, and purpose of Journal Club articles, please see http://jneurosci.org/content/ preparing-manuscript\#journalclub.

\title{
Intermediate-Term Memory as a Bridge between Working and Long-Term Memory
}

\author{
Jan Kamiński \\ Department of Neurosurgery, Cedars-Sinai Medical Center, Los Angeles, California 90048, and Division of Biology and Biological Engineering, California \\ Institute of Technology, Pasadena, California 91125 \\ Review of Fiebig and Lansner
}

Working memory is the ability to maintain information in an active and readily available state for short periods of time. It is a key component of many cognitive processes, including inference, decisionmaking, mental calculations, and awareness. One of the dominant models of working memory postulates that memoranda are stored through persistent neuronal activity (Goldman-Rakic, 1995). This model is supported by numerous singleneuron recordings from different brain areas in animals using a variety of paradigms (Constantinidis et al., 2001; Warden and Miller, 2010). Recently, we have corroborated this hypothesis in humans at the single-neuron level (Kamiński et al., 2017). However, results from other studies have led to the proposition of alternative models of working memory. Recently, Lundqvist et al. (2016) recorded local field potentials and single neurons in the prefrontal cortex of macaque monkeys performing a working memory task and found that information in working memory could be maintained through neuronal activity linked to discrete bursts of gamma oscillations. Additionally, Stokes et al. (2013) in another macaque study did not observe stimulus-specific persistent activ- ity in their recordings, and instead suggested that working memory was encoded through complex neuronal dynamics. This led to the proposition that synaptic changes, which are not visible in singleneuron recordings, may represent content held in working memory (the "activitysilent working memory" hypothesis; Stokes, 2015).

In a recent issue of The Journal of Neuroscience, Fiebig and Lansner (2017) presented a simplified neuronal model of cortical layers $2 / 3$ that incorporates features suggested by the experimental work of both Lundqvist et al. (2016) and Stokes et al. (2013). The model proposes that information in working memory is carried by discrete bursts of gamma oscillations rather than by continuous neuronal activity. Additionally, it makes use of a Hebbian form of spike timing-dependent short-term synaptic plasticity to code activitysilent working memories. This last modification is important because it enables the Fiebig and Lansner (2017) network to encode and maintain novel information, which is a fundamental feature of working memory. Indeed, simulations demonstrated that after short (1 s) periods of encoding, the network successfully stored multiple novel items, with each being reactivated in a separate gamma burst. To make the process of encoding mimic how humans memorize lists of items, information was introduced sequentially to the network. Consequently, items that were encoded at the beginning of a sequence had to be maintained for a longer period than other items, but they were exposed to less competition from previously encoded items than from items presented later in the sequence. Although items presented at the end of the sequence were subjected to high competition, their maintenance time was shorter. Consistent with this, analysis of the retrieval performance of the network revealed that items presented at the beginning or end of the sequence were stored better than items encoded in the middle of the sequence. Such effects are observed in behavioral experiments, and they are referred to as primacy (better recall for the beginning of the list) and recency (better recall for the end of the list) effects (Kahana, 2012).

Primacy and recency effects are thought to rely on distinct neural mechanisms and brain regions. For example, in working memory tasks when subjects need to categorize target items as previously seen or not, only the recency effect is observed (Sternberg, 2016). Interestingly, the primacy effect (but not the recency effect) is disrupted in subjects with damage to the medial temporal lobe (MTL), a key structure for forming long-term memories (Hermann et al., 1996). The role of the MTL in the primacy effect has been supported by an fMRI study showing that test items that were presented at the beginning 


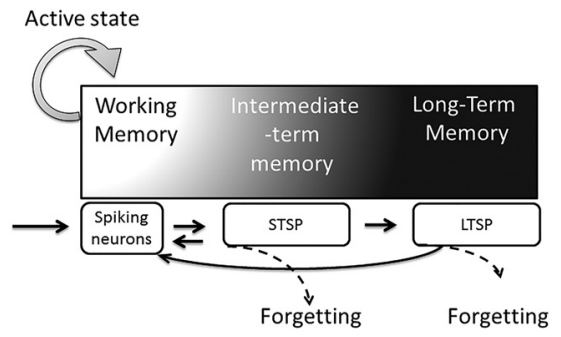

Figure 1. Intermediate-term memory is a state between working memory and long-term memory. After encoding, an item can be maintained in an active state through spiking activity. Short-term synaptic plasticity (STSP) allows information to be recovered if it temporarily drops out of the focus of attention. STSP also initiates the process of creating a stable memory, which requires longer-lasting processes like gene transcription. Finally, long-term synaptic plasticity (LTSP) creates stable long-term memories. Whenever information in working memory switch state to a latent form, the process of encoding it to long-term memories can be stopped in every stage and information is lost; however, if the process continues, the memory can be brought back to the active state.

of a list activated the hippocampus more strongly than those presented at the end (Talmi et al., 2005). Because the MTL is a key structure for forming long-term memories, these data support the hypothesis that the primacy effect relies heavily on a long-term memory system even when subjects need to memorize information for only a few seconds. This hypothesis is further supported by additional studies of MTL lesions, as follows: subjects with MTL lesions exhibited deficits in working memory tasks compared with control subjects whenever (1) they were presented with a distractor, (2) they maintained an amount of information close to their working memory capacity, or (3) the maintenance period was longer than a few seconds (Jeneson and Squire, 2012). These results suggest that whenever information held in working memory drops out from the focus of attention, because of distractions or long periods of maintenance, it can be recovered only when an area responsible for encoding declarative long-term memories is intact.

How might this interaction be achieved? One possible solution is presented in the Fiebig and Lansner (2017) model. In their simulation, well established neuronal patterns representing encoded items can be silent (not activated in gamma burst) for up to $8 \mathrm{~s}$ yet still be recalled as a result of synaptic plasticity. These simulations further showed that the persistent activity was not crucial for holding the content of working memory because the information in the network was stored for extended periods of time only by means of changing synaptic weights between neu- rons, which is similar to the mechanism observed during the very first stages of encoding long-term memories. Nevertheless, these synaptic weight changes, as implemented in the model, do not represent true long-term memory processes because they fade away quickly. Because of this property, this model is a hybrid that embodies characteristics of both working memory and long-term memory. This exemplifies the shift in neuroscience from studying working memory alone to realizing that long-term memory processes play a vital role in working memory tasks. Although psychology has long acknowledged that working memory and long-term memory are intimately interconnected (e.g., in the model of working memory by Cowan, 1988), this has only recently started to influence experimental paradigms in cognitive neuroscience.

One of the laboratories using this approach is Bradley Postle's group (LewisPeacock et al., 2012; LaRocque et al., 2013; Rose et al., 2016). In a series of experiments, they showed that whenever subjects shifted their focus of attention away from a particular item that is currently maintained in working memory, information about its category (e.g., spatial vs verbal) was no longer decodable using EEG or fMRI signals (Lewis-Peacock et al., 2012; LaRocque et al., 2013; Rose et al., 2016). Interestingly, this information could be reactivated when subjects were instructed to shift attention back to that item. Moreover, the information could be reactivated by transcranial magnetic stimulation, and this reactivation affected later performance (Rose et al., 2016). In a similar fMRI study, subjects memorized the spatial location of items (Sprague et al., 2016). Researchers showed that item location could be decoded using the BOLD signal. Again, when subjects were instructed to shift attention away from one of the items, the corresponding position was no longer decodable. Nevertheless, this information could be reactivated when subjects were instructed to shift their attention back to that item. Together, this shows that information can be maintained in a latent form invisible to both BOLD-fMRI and EEG and that this information can be brought back into an active state when needed. The study by Fiebig and Lansner (2017) indicates that short-term synaptic plasticity is a likely candidate for maintaining this latent state, whereas the active state is represented by spiking neurons.

In this latent state, memories are by definition not actively maintained-a fundamental characteristic of working memory-because they are out of the attentional focus. Neither are these memories permanently hardwired within the neuronal network. Rather, these memories represent a stage between working memory and long-term memory, a stage that molecular neurobiologists (Kandel et al., 2014) refer to as intermediate-term memory (Fig. 1). This intermediate-term memory state starts whenever an item drops out from the focus of attention (and is no longer represented by spiking neurons) and ends when a stable memory is created. Recent shifts in the neuroscientific research of working memory and new results emerging form these experiments led us to reevaluate how we think about memory systems. These new data question the validity of separate multistore systems and instead show that memory is a tightly interconnected continuum.

\section{References}

Constantinidis C, Franowicz MN, GoldmanRakic PS (2001) The sensory nature of mnemonic representation in the primate prefrontal cortex. Nat Neurosci 4:311-316. CrossRef Medline

Cowan N (1988) Evolving conceptions of memory storage, selective attention, and their mutual constraints within the human information-processing system. Psychol Bull 104:163-191. CrossRef Medline

Fiebig F, Lansner A (2017) A spiking working memory model based on Hebbian short-term potentiation. J Neurosci 37:83-96. CrossRef Medline

Goldman-Rakic PS (1995) Cellular basis of working memory. Neuron 14:477-485. CrossRef Medline

Hermann BP, Seidenberg M, Wyler A, Davies K, Christeson J, Moran M, Stroup E (1996) The effects of human hippocampal resection on the serial position curve. Cortex 32:323-334. CrossRef Medline

Jeneson A, Squire LR (2012) Working memory, long-term memory, and medial temporal lobe function. Learn Mem 19:15-25. CrossRef Medline

Kahana MJ (2012) Foundations of human memory. Oxford, UK: Oxford UP.

Kamiński J, Sullivan S, Chung JM, Ross IB, Mamelak AN, Rutishauser U (2017) Persistently active neurons in human medial frontal and medial temporal lobe support working memory. Nat Neurosci 20:590-601. CrossRef Medline

Kandel ER, Dudai Y, Mayford MR (2014) The molecular and systems biology of memory. Cell 157:163-186. CrossRef Medline

LaRocque JJ, Lewis-Peacock JA, Drysdale AT, Oberauer K, Postle BR (2013) Decoding attended information in short-term memory: an EEG study. J Cogn Neurosci 25:127-142. CrossRef Medline

Lewis-Peacock JA, Drysdale AT, Oberauer K, Postle BR (2012) Neural evidence for a dis- 
tinction between short-term memory and the focus of attention. J Cogn Neurosci 24:61-79. CrossRef Medline

Lundqvist M, Rose J, Herman P, Brincat SL, Buschman TJ, Miller EK (2016) Gamma and beta bursts underlie working memory. Neuron 90:152-164. CrossRef Medline

Rose NS, LaRocque JJ, Riggall AC, Gosseries O, Starrett MJ, Meyering EE, Postle BR (2016) Reactivation of latent working memories with transcranial magnetic stimulation. Science 354:1136-1139. CrossRef Medline
Sprague TC, Ester EF, Serences JT (2016) Restoring latent visual working memory representations in human cortex. Neuron 91: 694-707. CrossRef Medline

Sternberg S (2016) In defence of high-speed memory scanning. Q J Exp Psychol (Hove) 69:2020-2075. CrossRef Medline

Stokes MG (2015) “Activity-silent" working memory in prefrontal cortex: a dynamic coding framework. Trends Cogn Sci 19:394-405. CrossRef Medline

Stokes MG, Kusunoki M, Sigala N, Nili H, Gaffan
D, Duncan J (2013) Dynamic coding for cognitive control in prefrontal cortex. Neuron 78:364-375. CrossRef Medline

Talmi D, Grady CL, Goshen-Gottstein Y, Moscovitch M (2005) Neuroimaging the serial position curve: a test of single-store versus dual-store models. Psychol Sci 16:716-723. CrossRef Medline

Warden MR, Miller EK (2010) Task-dependent changes in short-term memory in the prefrontal cortex. J Neurosci 30:15801-15810. CrossRef Medline 